\title{
Estimating geochemical background values for naturally-occurring constituents in groundwater - A case study of fluoride in Alberta groundwater
}

\author{
RAPHAËL BONDU ${ }^{1}$, PAULINE HUMEZ ${ }^{2}$, WOLFRAM \\ KLOPPMANN $^{1}$, MARIA O. NAUMENKO-DÈZES ${ }^{1}$ AND \\ BERNHARD MAYER ${ }^{2}$ \\ ${ }^{1} \mathrm{BRGM}$ \\ ${ }^{2}$ University of Calgary \\ Presenting Author: bondu.raphael@gmail.com
}

Groundwater contamination is a major global concern, as groundwater is a vital source of drinking water in many parts of the world. Groundwater contaminants may originate from anthropogenic sources, natural sources, or a mix of both. Discriminating between natural and anthropogenic sources is critical for evaluating groundwater pollution and setting realistic clean-up goals and regulatory levels. For this purpose, the concept of natural geochemical background has been developed, with the objective to define a threshold level above which anthropogenic contamination can be expected. A variety of methods have been applied to estimate natural background concentrations of dissolved constituents in groundwater. However, the determination of background values has often been performed without considering the sources of the constituents of interest. A case study of fluoride in groundwater in parts of Alberta, Canada, is presented to illustrate the challenges associated with the estimation of geochemical background values for groundwater constituents derived from natural sources. More than 13,000 groundwater samples (mostly from private water supply wells) were obtained from the publicly-available Baseline Water Well Testing database [1]. Fluoride was found to exceed the Canadian drinking water guideline and provincial standard of $1.5 \mathrm{mg} / \mathrm{L}$ in $23.2 \%$ of the groundwater samples. There is no evidence that $\mathrm{F}$ was derived from anthropogenic sources, based on land use activities. Geochemical mapping indicates that $\mathrm{F}$ concentrations were influenced by the lithological characteristics of the aquifer units. Moreover, exploratory compositional data analysis suggests that $\mathrm{F}$ concentrations were largely controlled by the solubility of fluorite $\left(\mathrm{CaF}_{2}\right)$ and the desorption from mineral surfaces under alkaline conditions. Dissolved $\mathrm{F}$ concentrations were low in less geochemically evolved Ca-rich groundwater, and increased in more evolved Ca-depleted alkaline groundwater. Background F concentrations were estimated for different groundwater bodies, as determined based on major groundwater types and aquifer units. This case study highlights the importance of investigating the sources of groundwater constituents to establish geochemical background concentrations for relevant groundwater bodies.

[1] Alberta Energy Regulator (2006). EUB Directive 035. Baseline Water Well Testing Requirement for CBM Wells completed above the base of groundwater protection. 